\section{STROKE REHABILITATION SERVICES IN PAKISTAN: CURRENT STATUS AND FUTURE DIRECTIONS}

\section{Sahibzada Nasir Mansoor', Farooq Azam Rathore ${ }^{2 \bowtie}$, Muhammad lkram'}

THIS ARTICLE MAY BE CITED AS: Mansoor SN, Rathore FA, Ikram M. Stroke rehabilitation services in Pakistan: current status and future directions. Khyber Med Univ J 2020; I2(4): 333-5. DOI: 10.35845/kmuj.2020.20446.

S troke is a leading cause of adult mortality and morbidity worldwide. The incidence of stroke is falling in developed countries, while on the rise in developing countries.' Pakistan is a low middleincome country with an underdeveloped health care system whose major focus is on the management of communicable diseases. $^{2}$ Epidemiological data on stroke in Pakistan is limited, based mostly on small samples reported from hospital data.

Due to the combined efforts of the Pakistan Society of Neurology, Pakistan Stroke Society and the Faculty of Neurology at the College of Physicians and Surgeons of Pakistan (CPSP), the number of neurologists and stroke medicine physicians in the country has increased in the last decade. ${ }^{4}$ Diagnosis, acute evaluation and management of stroke has also improved. Areas of noted progress include early recognition of signs and symptoms of stroke, timely evacuation to a hospital, early neurology consult, availability of brain imaging (Computed Tomographic scan and Magnetic Resonance Imaging) and access to treatments including tissue plasminogen activator and endovascular procedures. ${ }^{4}$ At present, this is available only in major cities and hospitals. Despite such improvements in acute stroke management, functional outcomes and community reintegration for stroke patients in Pakistan is generally inadequate, due largely in part to the lack of multi-disciplinary stroke rehabilitation services. We aim to describe the current status of stroke rehabilitation services in Pakistan and discuss the main challenges and barriers towards providing multi-disciplinary s t roke reh abilitation. Recommendations to overcome these challenges are also provided.

\section{Dynamics and Challenges of Stroke rehabilitation in Pakistan}

Stroke rehabilitation is a multidisciplinary, goal-directed coordinated effort requiring expertise of different rehabilitation professionals, including physicians, nurses, physical and occupational therapists, speechlanguage pathologists, recreation therapists, psychologists, nutritionists, social workers, and others. ${ }^{5}$ Patients and their caregivers are also considered an important and integral part of the decision-making process in stroke rehabilitation.

The first challenge in stroke rehabilitation in Pakistan is lack of awareness regarding value of early, coordinated and multi-disciplinary stroke rehabilitation to improve functional outcomes and community reintegration of stroke survivors. Physicians in general are unaware of the value of stroke rehabilitation since disability management as a subject is not taught either to undergraduate medical students or post graduate residents in Pakistan. ${ }^{6}$ The general public also considers stroke to be an incurable disease with permanent disability, and do not seek an early rehabilitation consult.

The next issue is the lack of rehabilitation facilities and
I. Armed Forces Institute of Rehabilitation Medicine, Rawalpindi, Pakistan.

2. Department of Rehabilitation Medicine PNS Shifa Hospital, Karachi, Pakistan. Email凶: farooqrathore@gmail.com

$\begin{array}{ll}\text { Date Submitted: } & \text { June 12, 2020 } \\ \text { Date Revised: } & \text { November 16, 2020 } \\ \text { Date Accepted: } & \text { November I8, 2020 }\end{array}$

professionals. While the number of physical therapists and private physiotherapy clinics in the country has increased substantially in the last decade (due to the ballooning growth of physical therapy colleges), the number of stroke rehabilitation professionals in other disciplines remains low. ${ }^{7,8}$ The estimated number of trained rehabilitation medicine physicians in the country is 80 , the majority are in the armed forces with only a few working in the public sector. Most of the rehabilitation centers in the country are physiotherapy centers, offering only physical therapy instead of a multidisciplinary stroke rehabilitation involving different team members. Close coordination among different rehabilitation professionals in a stroke team is essential to maximize the effectiveness of stroke rehabilitation. Most of rehabilitation professionals in Pakistan work in isolation, and there is minimal coordination among them. Only a few institutions in the country have the necessary components and services to provide multi-disciplinary stroke rehabilitation at one site. All are in major cities and do not have outreach community rehabilitation programs for stroke patients.

Another major challenge is the lack of referrals for stroke rehabilitation. Even where stroke rehabilitation services are available a referral is either never made, delayed, or only directed to physiotherapy. Rehabilitation in Pakistan is still equated with physiotherapy and some form of exercise instead of multidisciplinary team work.' Instead of involving rehabilitation professionals at an early stage, patients are usually kept in the medical (or neurology wards where available) for a few days until medically stable. ${ }^{6}$ In the majority of stroke cases, particularly in public 
sector hospitals, patients are usually discharged to home with vague advice about 'doing exercise at home' and 'performing massage of the limbs'. Some patients are referred to physiotherapy department as outpatients. Those who have severe disability and ambulation impairment are not able to regularly attend the outpatient clinics due to lack of accessible transport and the cost and effort associated with daily transport of a stroke patient to the facility. This is further complicated by easy access to home-based physiotherapy. It is a common practice in Pakistan to hire a physical therapist for daily home exercises as it is more convenient and less expensive (charges range from PKR 600-1500; equivalent to 4-I0 USD per visit, Feb 2020 estimate). These homebased physical therapy sessions mostly consist of application of electrical muscle stimulations and hot packs, range of motion and passive stretching exercises in addition to some gait training. While this approach might facilitate some aspects of stroke recovery, other important components such as comprehensive management of spasticity, neuropathic pain and poststroke depression, occupational therapy for upper limb dysfunction, speech therapy for communication and swallowing and bladder management are not addressed. Therefore, the functional outcomes in many patients are under-achieved, despite many months of home-based physical therapy. Many of these patients remain wheelchair and 'bed bound' despite many months of regular home-based physical therapy.

Disability assessment and documentation of functional deficits and outcomes in stroke remains a major challenge in Pakistan. In most of the cases, only a neurological examination is done and documented at presentation and during follow-up visits. Although many validated stroke specific scales and tools to assess functional outcomes and quality of life are available, ${ }^{10}$ they are rarely used in Pakistan. Even most rehabilitation professionals do not perform formal documentation of functional outcomes and quality of life in stroke patients. Such practice is likely due to a combination of factors; lack of training in the use of assessment scales, lack of awareness about the assessment tools, and large numbers of patients to attend which makes it difficult for the rehabilitation professionals to find time to use assessment scales in their clinical practice.

All major stroke management guidelines throughout the world recommend stroke rehabilitation as a part of early stroke management." No national stroke care guidelines or strategy exists in Pakistan, a situation not dissimilar to other low-income countries. ${ }^{12}$

\section{The way forward}

To improve the present stroke rehabilitation services in Pakistan, there is need for greater and enhanced awareness and advocacy among the physicians, allied health care professionals, policy makers, governments, patients and care givers, to unite and strive for improvements in the services. More training slots for rehabilitation medicine should be created, and undergraduate medical students should have rotations in rehabilitation medicine departments to understand the value of disability assessment and stroke rehabilitation. Instead of the current fragmented model of stroke rehabilitation in the country, the concept of multidisciplinary stroke rehabilitation teams must be promoted. Multidisciplinary stroke rehabilitation units should be established in all large public sector hospitals, with a focus on mandatory early referrals of all stroke patients after they are medically stable. Local research on stroke rehabilitation should be supported and low-cost stroke rehabilitation protocols relevant to the social and cultural needs of Pakistan should be developed.

\section{CONCLUSION}

Overall, a concerted and coordinated effort among all stakeholders will be required to plan and implement these strategies, with the goal of all stroke patients having access to multidisciplinary stroke rehabilitation, thus improving functional outcomes and community reintegration.

\section{ACKNOWLEDGMENT}

The authors gratefully acknowledge the critical review of the manuscript by Colleen O'Connell MD FRCPC, Research Chief, Stan Cassidy Centre for Rehabilitation, Assistant Prof., Dalhousie University Faculty of Medicine, Fredericton, Canada

\section{REFERENCES}

I. Venketasubramanian N. Stroke in Developing Countries. In: Fisher M, Bogousslavsky J. (Eds) Current Review of Cerebrovascular Disease. 200I Current Medicine Group, London. DOI: 10.1007/978|-4684-000|-4_2|

2. Rathore FA, New PW, Iftikhar A. A report on disability and rehabilitation medicine in Pakistan: past, present, and future directions. Arch Phys Med Rehabil 2011;92(I):161-6. DOI: 10 . 1016/j.apmr.2010.10.004.

3. Farooq MU, Majid A, Reeves MJ, Birbeck GL. The epidemiology of stroke in Pakistan: past, present, and future. Int J Stroke. 2009 Oct; 4(5):38I-9. DOI: 10.1 III/j.17474949.2009.00327.x.

4. Anwar A, Saleem S, Aamir A, Diwan $M$. Organization of stroke care in Pakistan. Int J Stroke 2020 July: I $5(5): 565-6$. D O I: $10.1177 / 1747493019879663$.

5. Winstein CJ, Stein J, Arena R, Bates $B$, Cherney LR, Cramer SC, et al. Guidelines for adult stroke rehabilitation and recovery: a guideline for healthcare professionals from the American heart association/American stroke association. Stroke 2016;47(6):e98el69. DOI: I0.1 I6I/STR.00000000 00000098.

6. Rathore FA, Mansoor SN. Disability rights and management in Pakistan: time to face the bitter truth. J Coll Physicians Surg Pak 2019;29 (I2): I |3|-2. DOI: I0.2927|/jcpsp. 2019.12.1131.

7. Rathore FA, New PW, Iftikhar A. A report on disability and rehabilitation medicine in Pakistan: Past, present, and future directions. 
Arch Phys Med Rehabil 2011; 92:161-6. DOI: 10. 1016/j.apmr. 2010.10.004.

8. Rathore FA, Wasay M. Acute stroke care and long-term rehabilitation in Pakistan: Challenges and solutions. J Pak Med Assoc 2016;66(10): 12034.

9. Rathore MF, Rashid P, Butt AW, Malik AA, Gill ZA, Haig AJ. Epidemiology of spinal cord injuries in the 2005
Pakistan earthquake. Spinal Cord 2007;45(I0):658-63. DOI: 10. 1038/sj.sc.3 102023.

10. Stroke Assessment Scales. The Internet Stroke Center. [Accessed on: June II, 2020]. Available from URL: http://www.strokecenter. org/professionals/stroke-diagnosis/ stroke-assessment-scales/

II. Bates B, Choi JY, Duncan PW, Glasberg JJ, Graham GD, Katz RC, et al. Veterans affairs/ department of defense clinical practice guideline for the management of adult stroke rehabilitation care: executive summary. Stroke 2005;36(9):204956. DOI: |0.|I6I/0I.STR.0000| 80 432.73724.AD.

12. Rathore FA. The need and roadmap for stroke rehabilitation guidelines in Pakistan. Pak J Neuro Sci 2015; I0(2):3-5.

CONFLICT OF INTEREST

Authors declared no conflict of interest GRANT SUPPORT AND FINANCIAL DISCLOSURE NIL

(c) (1) (\$)

This is an Open Access article distributed under the terms of the Creative Commons Attribution-Non Commercial 2.0 Generic License.

KMUJ web address: www.kmuj.kmu.edu.pk

Email address: kmuj@kmu.edu.pk 